\title{
Is MGMT the best marker to predict response of temozolomide in aggressive pituitary tumors? Alternative markers and prospective treatment modalities
}

\author{
George Kontogeorgos ${ }^{1,2}$ (D) Eleni Thodou ${ }^{3}$ \\ Received: 3 October 2019 / Accepted: 15 October 2019/Published online: 13 November 2019 \\ (C) Hellenic Endocrine Society 2019
}

\section{Introduction}

The majority of pituitary tumors have a benign clinical course. However, a subset exhibits aggressive behavior, with early recurrence, rapid progression, and resistance to conventional therapies. Approximately, $0.2 \%$ are carcinomas showing frank malignancy and cause central nervous system and/or distant systemic metastases [1]. Currently, most pituitary adenomas can be successfully managed with modern surgical techniques and advanced medical treatment modalities, although the abovementioned subset may need adjuvant radiotherapy $[1$, 2]. Clinically aggressive refractory tumors nevertheless remain challenging to treat. Temozolomide (TMZ), which is an alkylating chemotherapeutic agent that inhibits tumor progression by blocking DNA replication, has today become a rational therapeutic option for aggressive/malignant pituitary tumors resistant to conventional therapeutic modalities [3-7]. Patients treated with TMZ show a remarkable improvement rate, with 5-year overall survival $[6,8]$. The cytotoxicity of TMZ depends on the expression of O-6 methylguanine DNA transferase (MGMT), a DNA repair enzyme. Since the presence of MGMT in tumor cells inactivates TMZ effectiveness, negative MGMT expression predicts responsiveness to therapy $[5,7,9]$, with several studies reporting a good correlation between the absence of MGMT expression and effectiveness

George Kontogeorgos

gkonto@med.uoa.gr

1 First Propaedeutic Department of Internal Medicine, Laikon Hospital, National and Kapodistrian University of Athens, 75 Mikras Asias Str., Athens 11527, Attica, Greece

2 Department of Pathology, "G. Gennimatas" Athens General Hospital, Athens, Greece

3 Department of Pathology, University of Thessaly, School of Medicine, Larissa, Greece of TMZ to refractory aggressive adenomas. TMZ is also capable of absorbing low MGMT stores, this being evident in tumors that showed negative or low MGMT expression which were removed from the responding patients $[10,11]$. However, given that some patients with MGMT-negative tumors do not respond [7, 9, 12], it is questionable whether immunohistochemistry for detection of MGMT yielded false-positive or false-negative results. The existence of such diagnostic dilemmas means that it is uncertain whether MGMT is the best predictive biomarker to select patients for treatment with TMZ. Currently, other markers are available which could be potential substitutes for MGMT.

This work attempts to shed light on the immunohistochemical detection of MGMT while seeking to illuminate the existing clinical controversies. In addition, it presents alternative biomarkers and also novel and emerging therapeutic interventions beyond TMZ for the treatment of refractory aggressive pituitary tumors.

\section{Controversial issues}

MGMT is currently considered as the gold standard to select candidate patients with carcinomas and aggressive adenomas for administration of TMZ. As a rule, absence of low MGMT expression predicts response to TMZ treatment $[5,6,8]$. However, in some patients with apparently negative MGMT, adenomas do not respond $[2,12]$. This lack of concordance of MGMT expression and response to TMZ treatment has not been fully elucidated. In a recent study where we described in detail the technical problems that may lead to false-low or false-negative MGMT expression, after direct application of the monoclonal antibody for immunohistochemical detection of MGMT, all but one adenomas (96\%) were negative. Surprisingly, after application of antigen retrieval protocols using either proteolytic enzymatic digestion with pronase or with pretreatment of Tris-EDTA buffer, another three of the 
adenomas that were initially negative changed to positive, while the remaining $21(84 \%)$ continued to yield negative results. This 3-fold increase in MGMT expression may explain the lack of effectiveness of TMZ therapy in patients with adenomas that are false-negative for MGMT [13].

Given the inconsistency of MGMT immunohistochemistry, some clinicians rely on elevated Ki-67 LI or strong expression of p53 to start administration of TMZ, without asking a pathologist to evaluate MGMT status [2, 14]. However, these markers cannot predict the effectiveness of treatment with TMZ [11, 15], several reports having shown no significant correlation between MGMT expression and Ki-67 LI with respect to the efficacy of TMZ treatment [15-17]. In addition, the assumption that atypical adenomas might have more aggressive clinical behavior has never been proven. For this reason, in the recent WHO edition of the classification of pituitary adenomas, the use of Ki-67 and p53 is not recommended for routine diagnosis [18]. As a result, the category "atypical adenomas" has been eliminated [19].

\section{Implication of technical issues}

Although specific monoclonal antibodies against MGMT are available, several parameters interfere with the immunohistochemical procedure, creating technical problems $[3,20]$. These parameters involve pre- and postanalytical conditions. Pre-analytical issues include delayed or prolonged formalin fixation of adenoma samples. Formaldehyde, although currently used as a standard method for tissue fixation, requires special attention so that problems in immunohistochemistry may be overcome. Moreover, the duration of storage of paraffin tissue blocks may be crucial. Post-analytical conditions include establishment of optimal working dilution of the antibody, which should be determined by the end user. In addition, low sensitivity of the antibody or the detection system may result in false immunoreactivity [13, 20]. Unmasking of hidden antigen sites in the tissue specimens requires pretreatment with antigen retrieval protocols [21]. The optimum protocol should be carefully evaluated and standardized in each pathology laboratory. It should be stressed that application of the appropriate antigen retrieval immunohistochemical protocol is crucial to obtain consistent results for patients who are candidates to receive TMZ therapy [13].

In general, negative or low MGMT expression is suggested as a predictive criterion to initiate treatment with TMZ. However, no consensus regarding the best system to evaluate MGMT expression at present exists [16, 20]. Furthermore, there is no agreement as to what should be the cut-off percentage of positive nuclei $[5,6,15]$. Other problems relate to the discrepancies in interobserver and intraobserver variations, which are difficult to eliminate.

\section{Advanced predictive biomarkers}

The precise mechanisms underlying MGMT expression remain to date largely unresolved. MGMT promoter methylation (MGMT-PM) represents as one of the proposed mechanisms responsible for suppression of MGMT expression, which results in reduced MGMT protein levels [22]. MGMT-PM tends to be common in aggressive pituitary tumors. The presence of MGMT-PM was investigated in a study including ten primary pituitary carcinomas, four disseminated metastases, and 12 silent type 3 pituitary adenomas. According to the recent WHO classification, the latter have been renamed "plurihormonal PIT-1 positive adenomas" and belong to the newly introduced "high risk adenomas" category [23]. Overall, 33\% of carcinomas exhibited homogenous MGMT-PM in both tumor and metastatic specimens, while low immunohistochemical MGMT expression was noted in $50 \%$ of them. Regarding the silent subtype 3 pituitary adenomas, $42 \%$ of them showed MGMT-PM, while MGMT immunostaining was predominately negative (92\%) [24]. Although an inverse correlation between MGMT-PM and MGMT immunohistochemistry was observed in some studies, the role of regulation of MGMT expression in pituitary tumors remains controversial [12, 24, 25]. In contrast to MGMT expression, the technical problems related to MGMT immunohistochemistry mentioned above have no effect on the evaluation of MGMT-PM status. Thus, the method is considered to be a more reliable option than immunohistochemistry for MGMT [20]. However, the complexity of MGMT regulatory mechanisms underlines the need for more in-depth research into the relationship between MGMT changes and patient response to TMZ [24].

The DNA mismatch repair (MMR) proteins, MLH1, MSH2, and MSH6 (MutS homolog 2 and MutS homolog 6, respectively), serve as alternative markers to MGMT to predict response to TMZ therapy. In the MMR pathway, heterodimers of MSH2 and MSH6 detect DNA base mismatches due either to errors in DNA replication or to DNA damage. During DNA synthesis, this pathway activates the G2-M DNA damage checkpoint and stimulates apoptotic mechanisms $[20,26]$. Expression of MMR proteins in aggressive pituitary tumors is linked to the effectiveness of TMZ treatment [15]. Nuclear immunoexpression of MSH6 correlates with a significant response to treatment with TMZ [17]. Patients with MSH6 positive tumors are responders to TMZ, whereas others with immunonegative tumors do not respond [11]. Unfortunately, many patients eventually develop resistance to treatment with TMZ. It is notable that adenomas removed from patients who responded to treatment show depletion of MSH6 immunoreactivity [16]. However, a recent study reports no differences in MSH6 immunoreactivity between adenomas from recurrent cases and from patients in remission [12]. In addition to MSH6, loss of MSH2 was 
observed in a patient who developed rapid resistance to TMZ [27]. Conceivably, loss of MSH2 and MSH6 expression occurring during tumor progression may explain the development of resistance to TMZ treatment.

\section{Novel and emerging treatment modalities}

A novel therapy that has recently emerged to manage patients with aggressive tumors who developed resistance to TMZ is currently the recommended first-line chemotherapy. Bevacizumab is an antiangiogenic drug targeting the vascular endothelial factor (VEGF). Bevacizumab inhibits angiogenesis, resulting in the suppression of tumor growth. The drug was recently applied either as monotherapy or in combination with TMZ in two patients, one of them with a clinically aggressive silent corticotroph adenoma subtype 2 , the other with a functioning corticotroph carcinoma immunoreactive for VEGF. Bevacizumab stopped tumor progression for 26 months and 5 years of follow-up, respectively [28, 29]. It should be noted that VEGF expression predicts a favorable outcome of treatment. Therefore, immunohistochemical evaluation of VEGF should be applied before embarking on antiVEGF treatment [28].

Tyrosine kinase inhibitors (TKI) belong to the ErbB family, which includes epidermal growth factor receptor (EGFR). Acting through the ErbB signaling pathway, TKI lead to reduced TK phosphorylation of targeted proteins. Up to twothirds of patients with Cushing's disease show ubiquitinspecific protease 8 mutations that may underlie the increase in EGFR signaling in corticotroph tumors [30]. Gefitinib, an EGFR-targeting tyrosine TKI, has therapeutic efficacy in corticotroph adenomas, which predominately show nuclear expression of EGFR. Gefitinib blocks EGFR activity, inhibits tumor cell proliferation, and induces apoptosis. Treatment of corticotroph adenomas with gefitinib leads to decreased tumor volume and corticosterone levels [31]. Lapatinib, an oral drug which is a EGFR/ErbB2 tyrosine kinase inhibitor, has been administrated to six patients with aggressive lactotroph adenomas who have been treated with the maximally tolerated dopamine agonist therapy. After 6 months, tumor size was decreased in one patient and prolactin (PRL) levels were reduced up to $42 \%$ in three other subjects. EGFR and ErbB2 immunohistochemical expression was not detectable in three tumors and did not correlate with treatment response. The results suggest that EGFR/ErbB2-targeted therapy with lapatinib may control continued tumor growth of aggressive lactotroph adenomas [32].

Immune checkpoint inhibitors (ICPIs) may be another option for the treatment of aggressive pituitary tumors. Only a single case of a patient with corticotroph carcinoma treated consecutively with nivolumab and ipilimumab (anti-CTLA-4 and anti-PD-L1 monoclonal antibodies, respectively) has been reported. After the treatment, a 59\% decrease of primary tumor volume and $92 \%$ of the main liver metastasis volume was noted, while the levels of plasma ACTH were decreased. The tumor samples retained immunohistochemical expression for MSH6 and PD-L1 staining in $<1 \%$ of tumor cells. After 6 months' therapy, the patient continued to respond [33]. Therefore, ICPIs constitute a potential alternative for the treatment of aggressive pituitary tumors, particularly in patients resistant to TMZ.

Everolimus (EVE) is an oral mTOR inhibitor. After binding to a FKBP12, the drug inhibits mTOR and its downstream signaling cascade resulting in decreased protein synthesis, reduced cell growth, and cell cycle arrest. To date, EVE has been tested in six patients with aggressive pituitary tumors. Three patients, one with a lactotroph adenoma and two with a corticotroph adenoma, who were treated with EVE in combination with other treatment modalities, showed transient stability for 5 to 12 months [34-37]. Given that the number of cases is very low, it remains to be clarified whether mTOR inhibitors could be useful to treat patients with highly aggressive, refractory pituitary tumors who failed to respond to other treatment modalities, including TMZ.

In conclusion, significant progress has been made over the past decade in the treatment of aggressive pituitary tumors. Considering the importance of immunohistochemistry in the detection of predictive markers, knowledge concerning the technical drawbacks leading to false-negative results may explain the current clinicopathological controversies. Other markers, such as MSH6, might be better alternatives to MGMT. Emerging treatment modalities beyond TMZ, such as anti-VEGF therapy and other novel and apparently promising therapeutic options, are opening up new horizons for the future management of aggressive pituitary tumors.

\section{References}

1. Kaltsas GA, Nomikos P, Kontogeorgos G, Buchfelder M, Grossman AB (2005) Diagnosis and management of pituitary carcinomas. J Clin Endocrinol Metab 90(5):3089-3099. https://doi. org/10.1210/jc.2004-2231

2. Raverot G, Castinetti F, Jouanneau E, Morange I, Figarella-Branger D, Dufour H, Trouillas J, Brue T (2012) Pituitary carcinomas and aggressive pituitary tumours: merits and pitfalls of temozolomide treatment. Clin Endocrinol 76(6):769-775. https://doi.org/10.1111/ j.1365-2265.2012.04381.x

3. Fadul CE, Kominsky AL, Meyer LP (2006) Long-term response of pituitary carcinoma to temozolomide. Report of two cases. J Neurosurg 105(4):621-621. https://doi.org/10.3171/jns.2006.105. 4.621

4. Lim S, Shahinian H, Maya MM, Yong W, Heaney AP (2006) Temozolomide: a novel treatment for pituitary carcinoma. Lancet Oncol 7(6):518-520. https://doi.org/10.1016/S1470-2045(06) 70728-8

5. Kovacs K, Horvath E, Syro LV, Uribe OH, Penago LC, Ortiz LD, Fadul CE (2007) Temozolomide therapy in a man with an 
aggressive prolactin-secreting pituitary neoplasm: morphological findings. Hum Pathol 38(1):185-189. Erratum in: Hum Pathol 38(3):526. https://doi.org/10.1016/j.humpath.2006.07.014

6. Syro LV, Scheithauer BW, Ortiz LD, Fadul CE, Horvath E, Rotondo F, Kovacs K (2009) Effect of temozolomide in a patient with recurring oncocytic gonadotrophic pituitary adenoma. Hormones (Athens) 8(4):303-306. https://doi.org/10.14310/horm. 2002.1247

7. Hagen C, Schroeder HD, Hansen S, Hagen C, Andersen M (2009) Temozolomide treatment of a pituitary carcinoma and two pituitary macroadenomas resistant to conventional therapy. Eur J Endocrinol 161(4):631-637. https://doi.org/10.1530/EJE-09-0389

8. Syro LV, Ortiz LD, Scheithauer BW, Lloyd RV, Lau Q, Gonzalez R, Uribe H, Cusimano M, Kovacs K, Horvath E (2011) Treatment of pituitary neoplasms with temozolomide: a review. Cancer 117(3): 454-462. https://doi.org/10.1002/cncr.25413

9. Kovacs K, Scheithauer BW, Lombardero M, McLendon RE, Syro LV, Uribe H, Fadul CE (2008) MGMT immunoexpression predicts responsiveness of pituitary tumors to temozolomide therapy. Acta Neuropathol 115(2):261-262. https://doi.org/10.1007/s00401-0070279-5

10. McCormack AI, Wass JA, Grossman AB (2011) Aggressive pituitary tumours: the role of temozolomide and the assessment of MGMT status. Eur J Clin Investig 41(10):1133-1148. https://doi. org/10.1111/j.1365-2362.2011.02520.x

11. Moshkin O, Syro LV, Scheithauer BW, Ortiz LD, Fadul CE, Uribe H, Gonzalez R, Cusimano M, Horvath E, Rotondo F, Kovacs K (2011) Aggressive silent corticotroph adenoma progressing to pituitary carcinoma: the role of temozolomide therapy. Hormones (Athens) 10(2):162-167. https://doi.org/10.14310/horm.2002.1307

12. McCormack AI, McDonald KL, Gill AJ, Clark SJ, Burt M, Campbell KA (2009) Low 06-methylguanine-DNA methyltransferase [p1] (mgmt) expression and response to temozolomide in aggressive pituitary tumors. Clin Endocrinol 71(2):226-233. https://doi.org/10.1111/j.1365-2265.2008.03487.x

13. Kontogeorgos G, Thodou E, Koutouroussiou M, Kaltsas G, Seretis A (2019) MGMT immunohistochemistry in pituitary tumors: controversies with clinical implications. Pituitary. https://doi.org/10. 1007/s11102-019-00993-5

14. Asimakopoulou A, Tzanela M, Koletti A, Kontogeorgos G, Tsagarakis S (2014) Long-term remission in an aggressive Crooke cell adenoma of the pituitary, 18 months after discontinuation of treatment with temozolomide. Clin Case Rep 2(1):1-3. https://doi.org/10.1002/ccr3.39

15. Bengtsson D, Schrøder HD, Andersen M, Maiter D, Berinder K, Feldt Rasmussen U, Krogh Rasmussen Å, van der Lely A, Petersson M, Johannsson G, Andersen M, Burman P (2015) Long-term outcome and MGMT as a predictive marker in 24 patients with atypical pituitary adenomas and pituitary carcinomas given treatment with temozolomide. J Clin Endocrinol Metab 100(4):1689-1698. https://doi.org/10.1210/jc.2014-4350

16. Zuhur SS, Tanik C, Karaman Ö, Velet S, Çil E, Öztürk FY, Özkayalar H, Müslüman AM, Altuntaş Y (2011) MGMT immunoexpression in growth hormone-secreting pituitary adenomas and its correlation with Ki-67 labeling index and cytokeratin distribution pattern. Endocrine 40(2):222-227. https://doi.org/10. 1007/s12020-011-9485-y

17. Hirohata T, Asano K, Ogawa Y, Takano S, Amano K, Isozaki O, Iwai Y, Sakata K, Fukuhara N, Nishioka H, Yamada S, Fujio S, Arita K, Takano K, Tominaga A, Hizuka N, Ikeda H, Osamura RY, Tahara S, Ishii Y, Kawamata T, Shimatsu A, Teramoto A, Matsuno A (2013) DNA mismatch repair protein (MSH6) correlated with the responses of atypical pituitary adenomas and pituitary carcinomas to temozolomide: the national cooperative study by the Japan Society for Hypothalamic and Pituitary Tumors. J Clin
Endocrinol Metab 98(3):1130-1136. https://doi.org/10.1210/jc. 2012-2924

18. Lloyd RV, Kovacs K, Young WF Jr, Farell WE, Asa SL, Touillas J, Kontogeorgos G, Sano T, Scheithauer BW, Horvath E (2004) Pituitary tumours: introduction. In: DeLellis RA, Heitz P, Lloyd RV, Eng C (eds) WHO Classification of Tumours, Pathology and Genetics, Tumours of Endocrine Organs. IARC Press, Lyon, pp 10-13

19. Osamura RY, Lopes MBS, Grossman A, Kontogeorgos G, Trouillas J (2017) Tumours of the pituitary gland. Introduction. In: Lloyd RV, Osamura R, Klöppel G (eds) WHO Classification of Tumours of Endocrine Organs, 4th end. IARC, Lyon, p 13

20. Micko ASG, Wöhrer A, Höftberger R, Vila G, Marosi C, Knosp E, Wolfsberger S (2017) MGMT and MSH6 immunoexpression for functioning pituitary macroadenomas. Pituitary 20(6):643-653. https://doi.org/10.1007/s11102-017-0829-3

21. Kontogeorgos G, Horvath E, Kovacs K, Coire C, Lloyd RV, Scheithauer BW, Smyth HS (2006) Morphologic changes of prolactin-producing pituitary adenomas after short treatment with dopamine agonists. Acta Neuropathol 111(1):46-52. https://doi. org/10.1007/s00401-005-1111-8

22. Esteller M, Hamilton SR, Burger PC, Baylin SB, Herman JG (1999) Inactivation of the DNA repair gene O6-methylguanineDNA methyltransferase by promoter hypermethylation is a common event in primary human neoplasia. Cancer Res 59(4):793-797

23. Kontogeorgos G, Kovacs K, Lloyd RV, Righi A (2017) Plurihormonal and double adenomas. In: Lloyd RV, Osamura R, Klöppel G (eds) WHO Classification of Tumours of Endocrine Organs, 4th end. Lyon, IARC, pp 39-40

24. Salehi F, Scheithauer BW, Kros JM, Lau Q, Fealey M, Erickson D, Kovacs K, Horvath E, Lloyd RV (2011) MGMT promoter methylation and immunoexpression in aggressive pituitary adenomas and carcinomas. J Neuro-Oncol 104(3):647-657. https://doi.org/10. 1007/s11060-011-0532-6

25. Jiang $\mathrm{XB}, \mathrm{Hu} \mathrm{B}, \mathrm{He} \mathrm{DS}$ (2015) Expression profiling of $\mathrm{O}^{6}$ methylguanine-DNA-methyl transferase in prolactinomas: a correlative study of promoter methylation and pathological features in 136 cases. BMC Cancer 15:644-651. https://doi.org/10.1186/ s12885-015-1595-0

26. Stojic L, Mojas N, Cejka P, Di Pietro M, Ferrari S, Marra G, Jiricny $\mathrm{J}$ (2004) Mismatch repair-dependent G2 checkpoint induced by low doses of SN1 type methylating agents requires the ATR kinase. Genes Dev 18(11):1331-1344. https://doi.org/10.1101/gad.294404

27. Murakami M, Mizutani A, Asano S, Katakami H, Ozawa Y, Yamazaki K, Ishida Y, Takano K, Okinaga H, Matsuno A (2011) A mechanism of acquiring temozolomide resistance during transformation of atypical prolactinoma into prolactin-producing pituitary carcinoma: case report. Neurosurg 68(6):E1761-E1767. https://doi.org/10.1227/NEU.0b013e318217161a

28. Ortiz LD, Syro LV, Scheithauer BW, Ersen A, Uribe H, Fadul CE, Rotondo F, Horvath E, Kovacs K (2012) Anti-VEGF therapy in pituitary carcinoma. Pituitary 15(3):445-449. https://doi.org/10. 1007/s11102-011-0346-8

29. Touma W, Hoostal S, Peterson RA, Wiernik A, SantaCruz KS, Lou E (2017) Successful treatment of pituitary carcinoma with concurrent radiation, temozolomide, and bevacizumab after resection. $\mathrm{J}$ Clin Neurosci 41:75-77. https://doi.org/10.1016/j.jocn.2017.02. 052

30. Ben-Shlomo A, Cooper O (2017) Role of tyrosine kinase inhibitors in the treatment of pituitary tumours: from bench to bedside. Curr Opin Endocrinol Diabetes Obes 24(4):301-305. https://doi.org/10. 1097/MED.0000000000000344

31. Fukuoka H, Cooper O, Ben-Shlomo A, Mamelak A, Ren SG, Bruyette D, Melmed S (2011) EGFR as a therapeutic target for human, canine, and mouse ACTH-secreting pituitary adenomas. J Clin Invest 121(12):4712-4721. https://doi.org/10.1172/JCI60417 
32. Cooper O, Bonert V, Rudnick J, Pressman B, Melmed S (2019) EGFR/ErbB2 targeted therapy for aggressive prolactinomas. J Endocr Soc 3(sup 1):SUN-442. https://doi.org/10.1210/js.2019SUN-442

33. Lin AL, Jonsson P, Tabar V, Yang TJ, Cuaron J, Beal K, Cohen M, Postow M, Rosenblum M, Shia J, DeAngelis LM, Taylor BS, Young RJ, Geer EB (2018) Marked response of a hypermutated ACTH-secreting pituitary carcinoma to ipilimumab and nivolumab. J Clin Endocrinol Metab 103(10):3925-3930. https://doi.org/10. 1210/jc.2018-01347

34. Sajjad EA, Zieliński G, Maksymowicz M, Hutnik Ł, Bednarczuk T, Włodarski P (2013) mTOR is frequently active in GH-secreting pituitary adenomas without influencing their morphopathological features. Endocr Pathol 24(1):11-19. https://doi.org/10.1007/ s12022-012-9230-y

35. Monsalves E, Juraschka K, Tateno T, Agnihotri S, Asa SL, Ezzat S, Zadeh G (2014) The PI3K/AKT/mTOR pathway in the pathophysiology and treatment of pituitary adenomas. Endocr Relat Cancer 21(4):R331-R344. https://doi.org/10.1530/ERC-140188

36. Donovan LE, Arnal AV, Wang S-H, Odia Y (2016) Widely metastatic atypical pituitary adenoma with mTOR pathway STK11 (F298L) mutation treated with everolimus therapy. CNS Oncol 5(4):203-209. https://doi.org/10.2217/cns-2016-0011

37. Zhang D, Way JS, Zhang X, Sergey M, Bergsneider M, Wang MB, Yong WH, Heaney AP (2019) Effect of everolimus in treatment of aggressive prolactin-secreting pituitary adenomas. J Clin Endocrinol Metab 104(6):1929-1936. https://doi.org/10.1210/jc. 2018-02461

Publisher's note Springer Nature remains neutral with regard to jurisdictional claims in published maps and institutional affiliations. 